\section{THE ACTION OF TARTAR EMETIC IN BILHARZIASIS.}

\section{To the Editor of THE LANCET.}

SIR,-In papers and annotations dealing with the cure of bilharzia with tartar emetic the point has been mentioned as to whether the worms or the eggs are first affected by this drug. For several years before the discovery of the tartar emetic cure I had been experimenting with various methods, and I had found one which in my hands gave very encouraging results. The starting point of this treatment was that I had observed that the urine of bilharzial patients, who from any cause had to be in bed on a fluid diet, improved considerably, but that soon after they received full diet again the previous condition was restored. I regarded this diminution of the external evidence of the bilharzial infection as due to the fact that, owing to the reduction in the quality of the portal blood, the worms were producing eggs in greatly reduced quantity. There can have been no question of any direct effect on the eggs from such treatment. The decrease was noticeable after about a week of treatment. I received confirmation, or what I looked on as confirmation, of this view from the fairly numerous cases of Egyptian fellaheens, who, being accustomed to live very frugally at home, complained, shortly after their arrival in the Sudan, where they were comparatively richly fed, that their urinary trouble, which before had been slight or unnoticed, had become tiresome and severe. In the course of my experiments $I$ was able to reduce or increase the number of eggs passed practically at will.

My view which developed from these observations was that the usual time for a crop of eggs to take from the worm to the urine was five to seven days by the normal routes, but, of course, many eggs missed their way and took much longer to arrive. As the improvement in cases of bilharziasis takes place in much about the same time, I have always considered that the first effect of tartar emetic was to limit the production of eggs. In the article by Archibald and Innes in the Journal of Tropical Medicine, April 1st, 1919 , on a so-called fatal result from tartar emetic treatment of bilharziasis in an Egyptian soldier who died of influenza, bilharzial eggs were found in the tissues but no worms could be discovered. Further, I find that the eggs in cases of Bilharzia IIansoni take a longer time than in vesical bilharziasis to become brown and granular, and this points again to the worms and not the eggs being primarily affected.

$$
\text { I am, Sir, yours faithfully, }
$$

$$
\text { V. S. HoDson, }
$$

Director, Khartoum Civil Hospital.

Khartoum, June 16th, 1921 .

\section{" CIRCULAR 202."}

To the Editor of THE LANCET.

SIR,-Circular 202 on the Prevention and Treatment of Venereal Diseases, recently issued by the Ministry of Health, must, on the whole, be welcomed by those who believe that instruction in the methods of self-disinfection is a necessary health measure for the prevention of venereal disease. True, the circular states that the Government, because of the moral and social considerations involved, cannot give its "official support" to self-disinfection, yet, although self-disinfection in exact terms is disavowed, the principle of self-disinfection is strongly supported. This is seen in a later paragraph, where the Minister advises the issue of leaflets warning the public that it is the duty of all individuals who have incurred the risk of contracting disease to cleanse themselves immediately and thoroughly, and thereby diminish the risk. " Cleansing immediately and thoroughly," presumably with soap and water, is nothing else but a form of self-disinfection; the use of soap and water is neither so effective nor in many cases so readily available as is the employment of a portable disinfectant such as permanganate of potash, but the principle in the two cases is identical. The circular is therefore a distinct advance on past pronouncements of the Ministry on the subject.

But there is an even greater concession. Iater on in the circular it is stated that the Minister considers it desirable to state that he is advised that a chemist does not commit an offence against any Act of Parliament by selling substances "capable of being used as disinfectants against venereal diseases." The clear inference to be drawn from this statement is that although the Government can give no official support to self-disinfection, yet the Minister is so alive to its value that he goes out of his way to add a paragraph directly encouraging the practice.

Although some of us may regret that the support given to self-disinfection is not so whole-hearted as we could have wished, yet allowance must be made for a Government which is attempting to deal with a subject upon which many people hold strong convictions. Experience has taught me to recognise that the advocacy of a policy of self-disinfection, on first consideration, always arouses strong opposition in certain quarters because of the conviction that it may prove an incentive to immorality, but I believe that if only the whole facts of the case are clearly and calmly discussed the opposition is to a great extent disarmed. I have formed this opinion as a result of the course of events in Portsmouth, and $I$ am further strengthened in this opinion by the fact that the Special Committee of the National Birthrate Commission, a body composed under the chairmanship of the Bishop of Birmingham of individuals whose names alone are a sufficient guarantee that no practice which tended to encourage vice would ever receive the slightest recognition, have reported strongly in favour of a policy of instructing the public in the methods of self-disinfection.

I regard Circular 202 as a step in the right direction, and $I$ feel confident that it will not be long before a still further advance is made towards the policy so strongly advocated by the medical profession as being the best practical means for controlling the most serious menace at the present time to the health of the nation.

I am. Sir, yours faithfully,

$$
\text { A. Mearns Fraser, }
$$

June 28th, 1921. Medical Officer of Health, Portsmouth.

\section{DIGITALIS AND THE PERIPHERAL CIRCULATION.}

\section{To the Editor of THE LANCET.}

Sir,-Dr. W. J. Grant, in The LANCET of June 25th, still entertains misgivings in regard to many errors in physics which $I$ am supposed to have committed. Let us define the issue. One of the facts I attempted to establish in my paper is that under the influence of digitalis we often get a decline in the systolic and diastolic pressure at the very moment when the output of the heart per single contraction is increased. I maintain that it is a physical possibility to obtain an increased volume of flow per unit of time through the circulation under these conditions. My reasons for such an assumption are as follows:-

1. During the systole the velocity of the blood in any part of the arterial circulation is about three to four times greater than during the diastole. It follows from this that if the systolic output is increased a greater amount of fluid in the arterial system circulates at a greater speed than under normal conditions. In these circumstances the total volume of blood leaving the arterial system in a given time might be greater than normal. On this supposition the arteries would contain less blood during the diastole than normally. But as the systolic pressure is made up, (other conditions remaining the same), of the volume of blood contained in the arteries during the diastole plus systolic output, it follows that this pressure might become lower than normal, although the single 